\title{
High Rate Lithium Metal Plating and Stripping on Solid Electrolyte Using Porous Current Collector with High Aperture Ratio
}

Shota Shinzo, Eiji Higuchi, Masanobu Chiku*, Akitoshi Hayashi, and Hiroshi Inoue

Department of Applied Chemistry, Graduate School of Engineering, Osaka Prefecture

University, Sakai, Osaka 599-8531, Japan

Email: chiku@chem.osakafu-u.ac.jp 

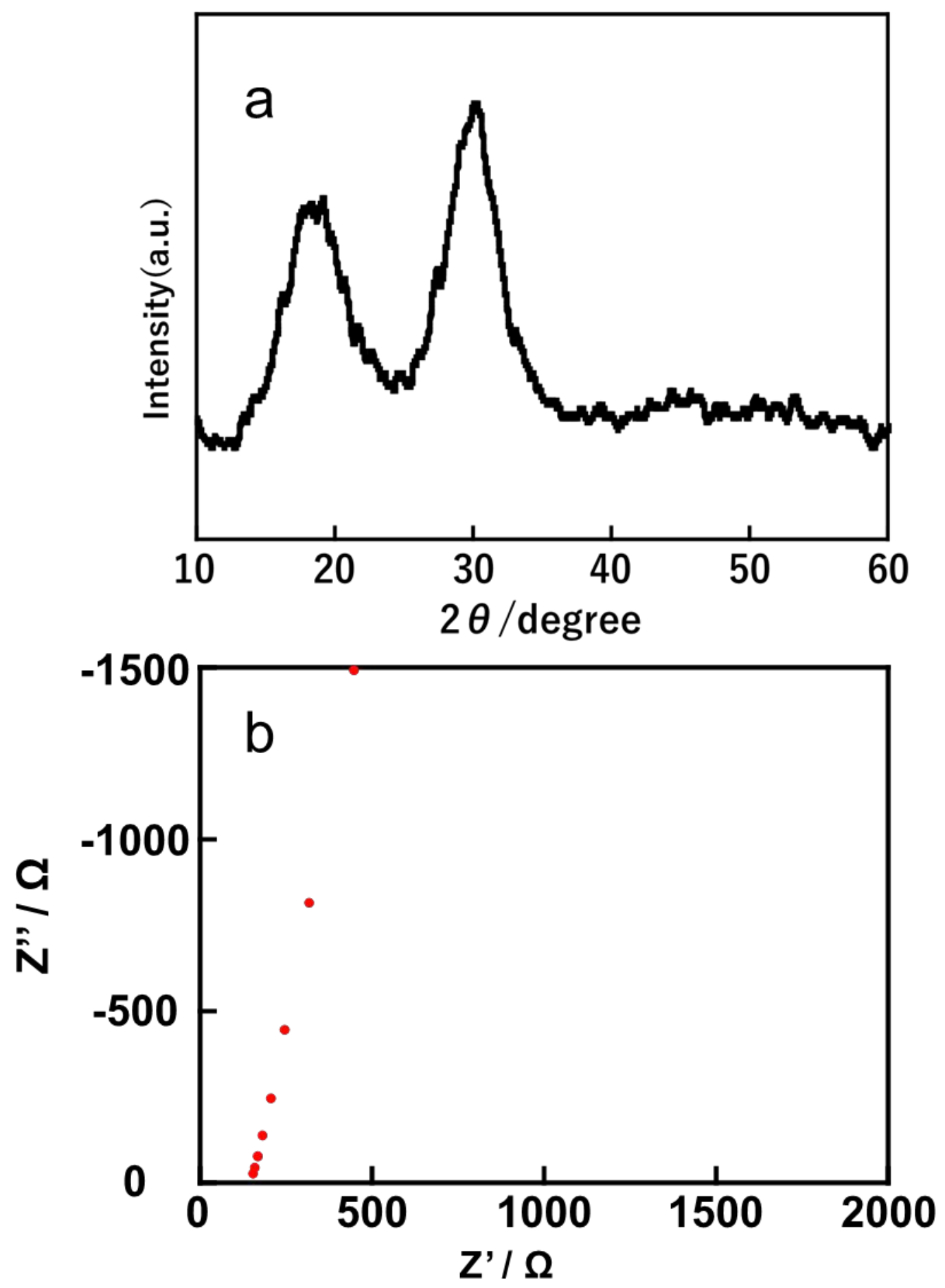

Figure S1 XRD pattern (a) and Nyquist plot (b) of $\mathrm{Li}_{3} \mathrm{PS}_{4}$. 

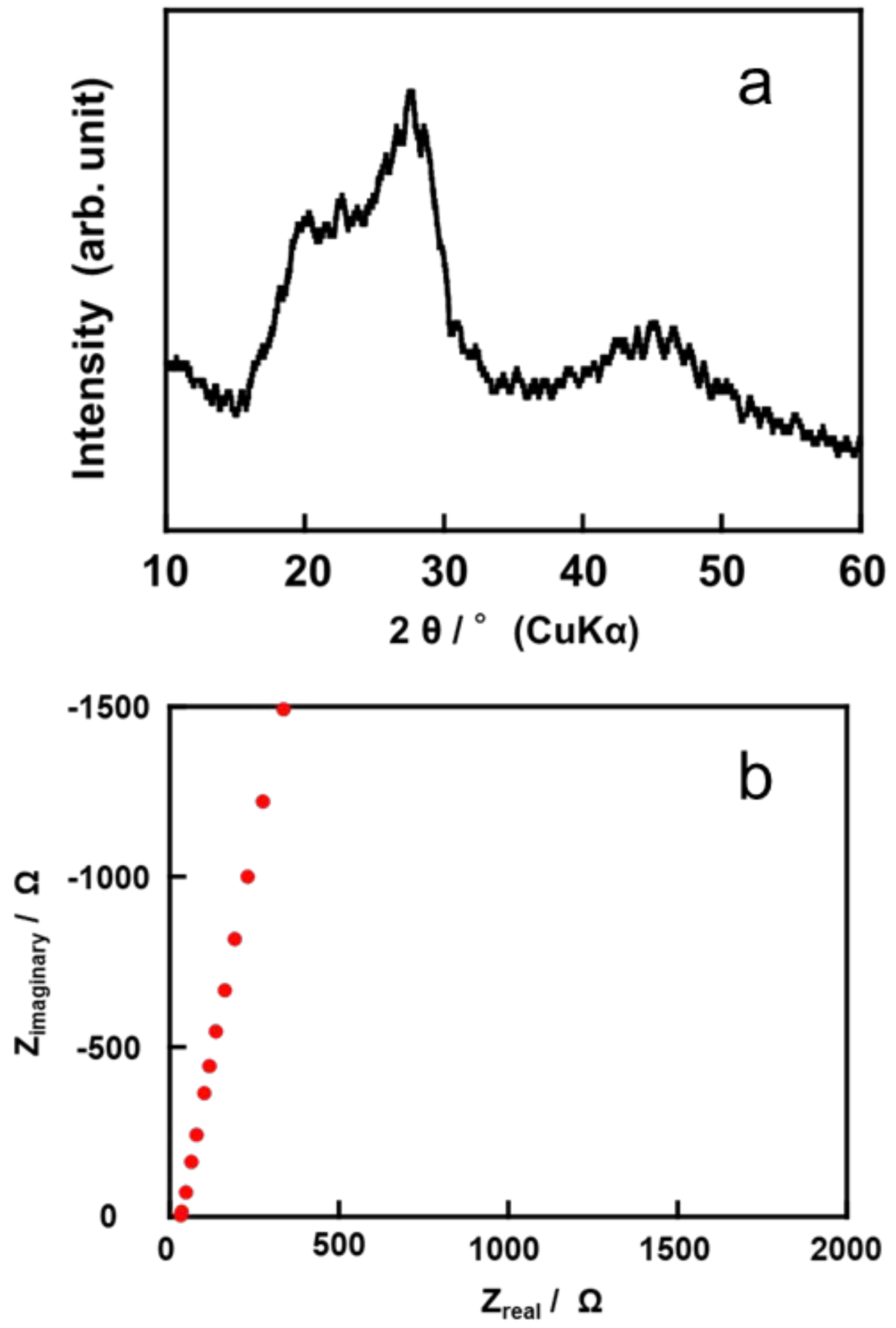

Figure S2 XRD pattern (a) and Nyquist plot (b) of $54 \mathrm{Li}_{3} \mathrm{PS}_{4}-46 \mathrm{LiI}$. 


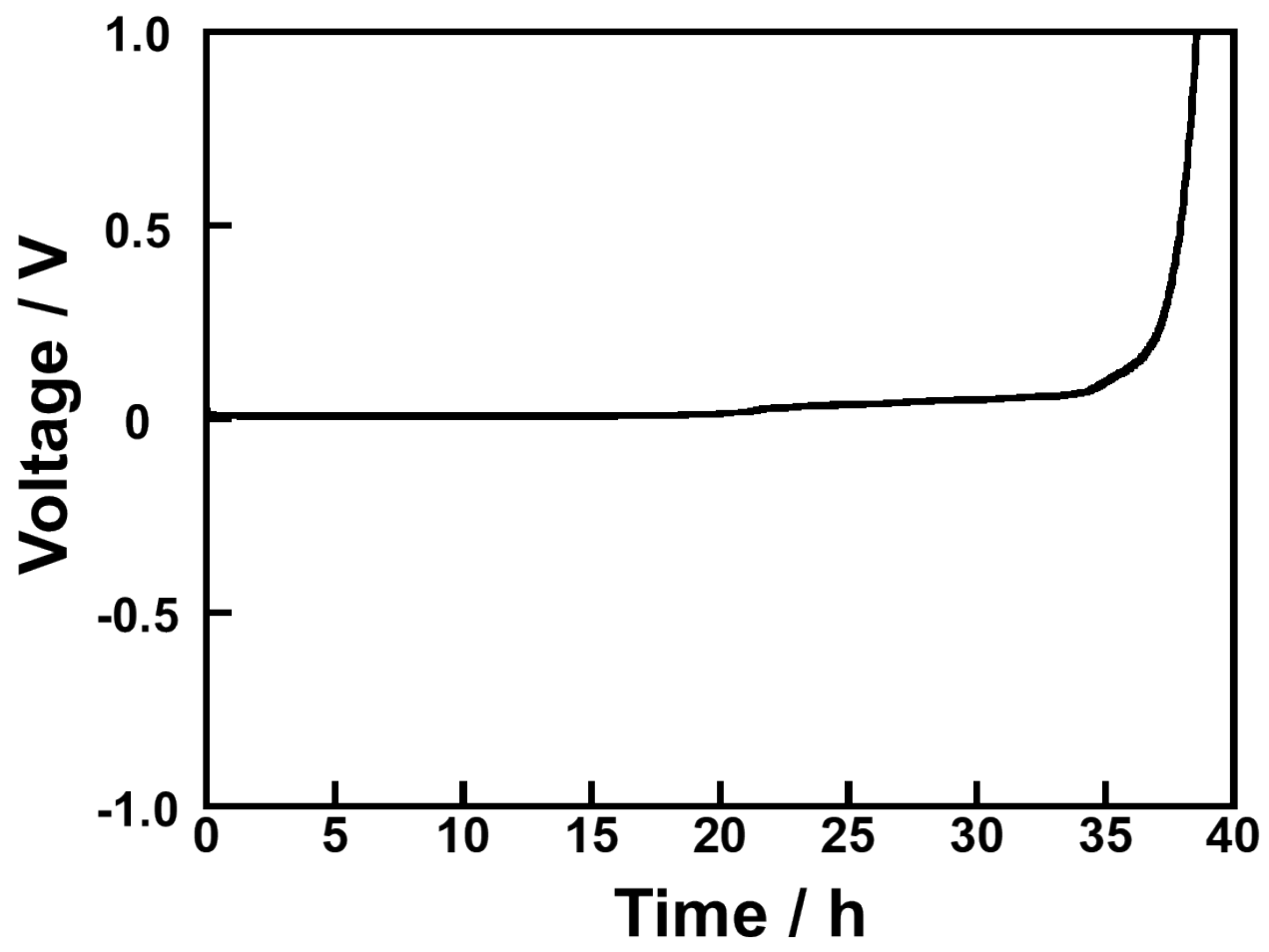

Figure S3 Galvanostatic test of In|LPSLI|Li-In cell for evaluating Li-In capacity under at $30{ }^{\circ} \mathrm{C}$ Current density : $0.1 \mathrm{~mA} \mathrm{~cm}^{-2}$. 


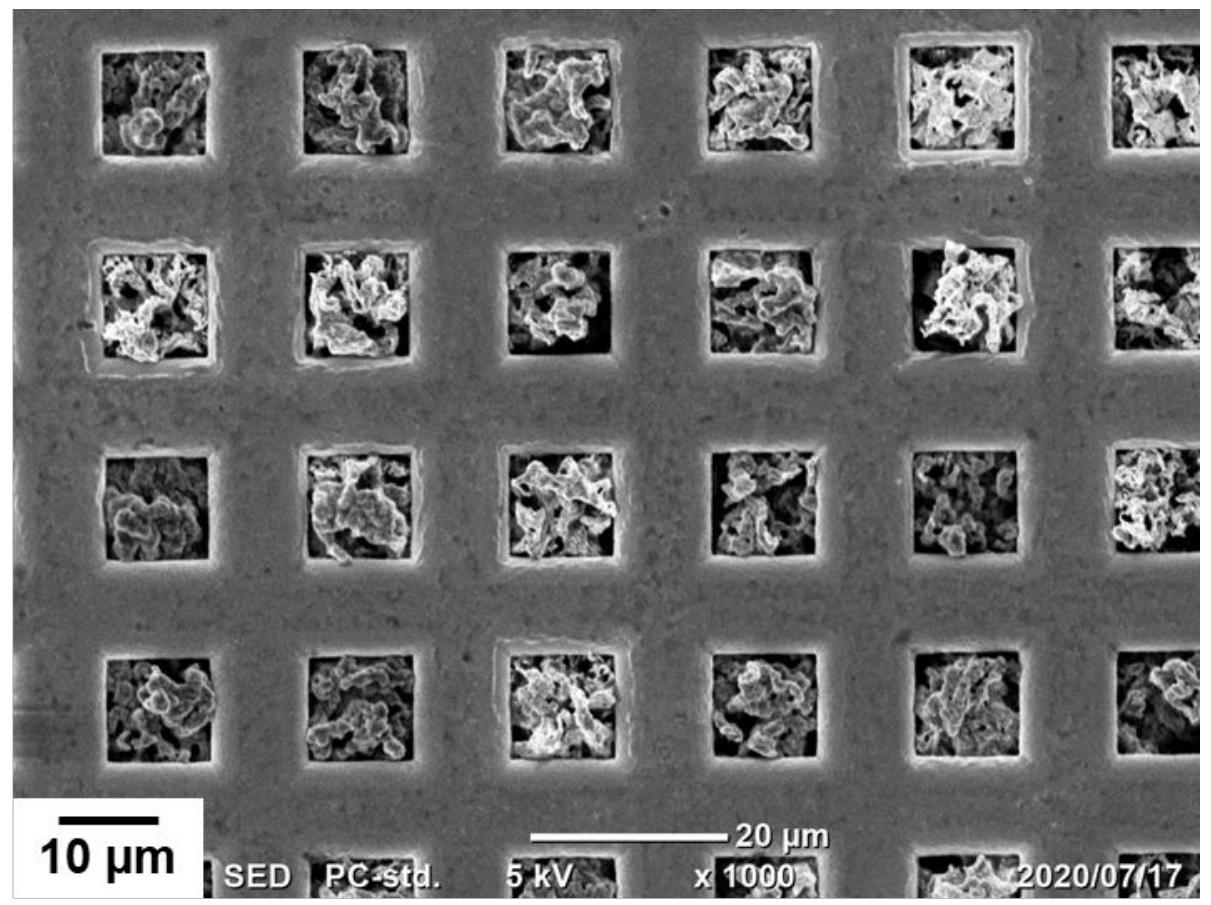

Figure S4 SEM image of the back side of the PCC-11 after 15 cycles of plating/stripping for PCC11|LPS|Li-In, followed by detaching the PCC-11 from the SE. 

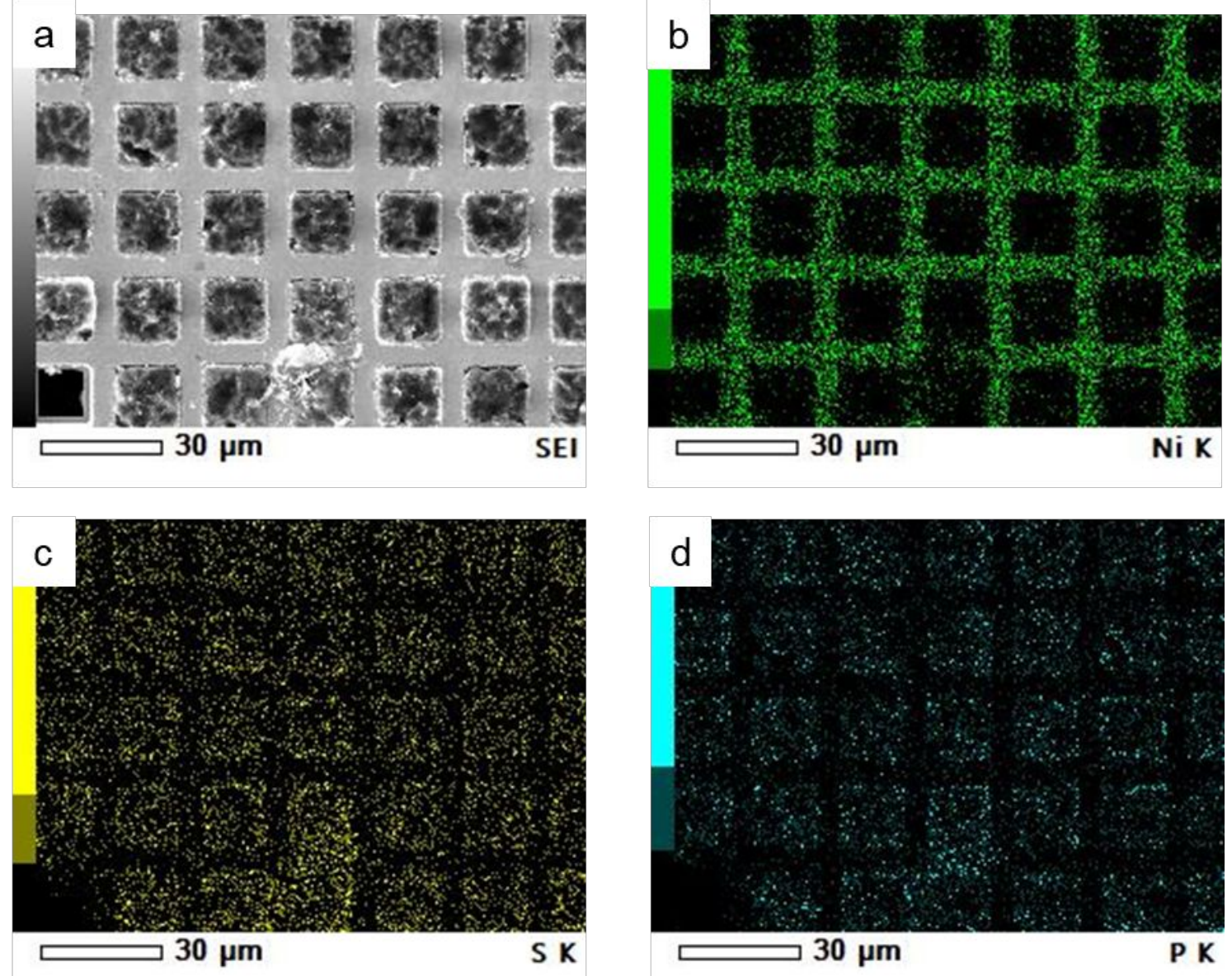

Figure S5 (a) SEM image and (b, c, d) EDS maps of the front side of the PCC-11 after 15 cycles of plating/stripping for PCC-11|LPS|Li-In, followed by detaching the PCC-11 from the SE. 

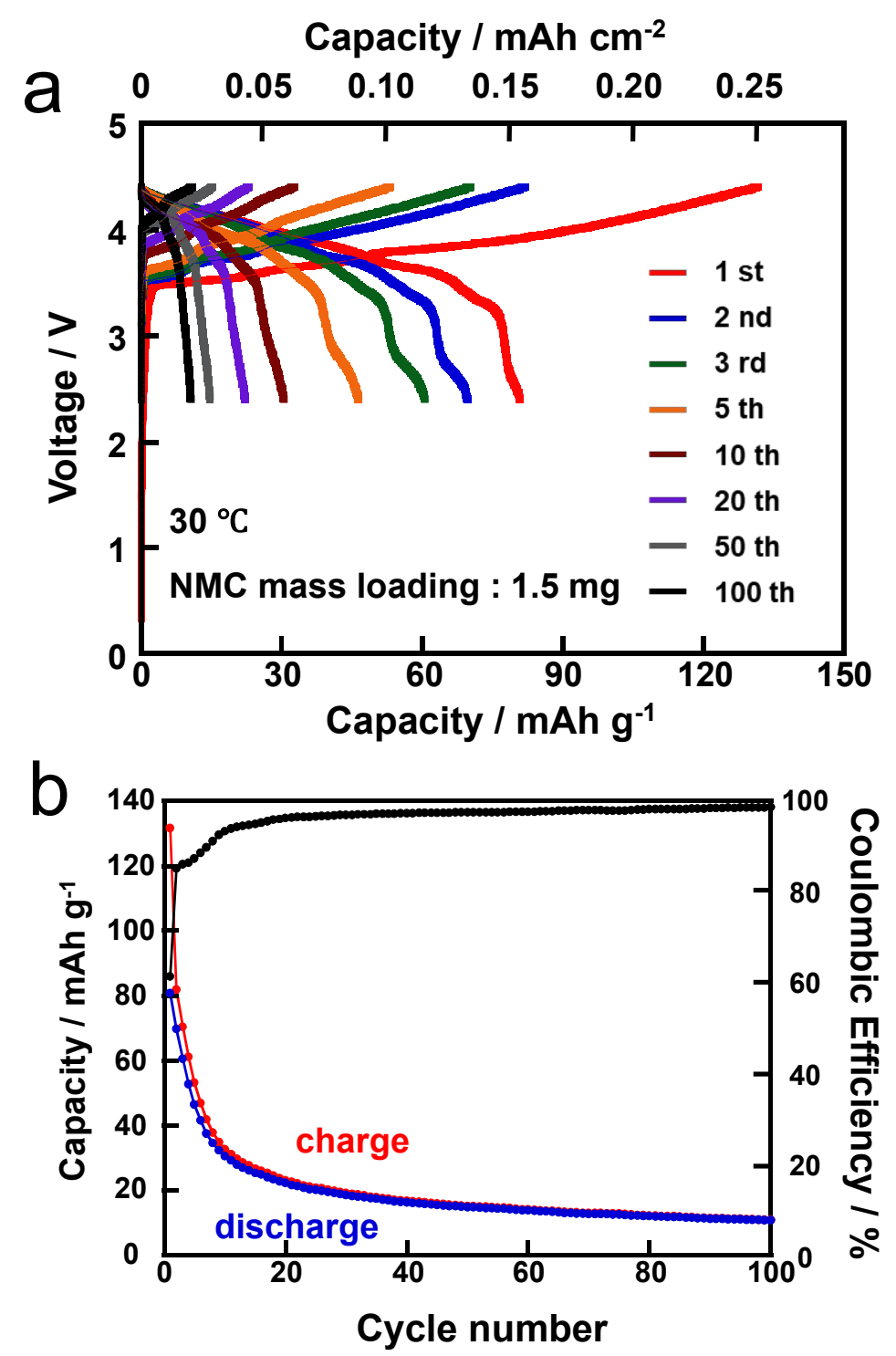

Figure S6 Voltage profile (a), Cycling performances and Coulombic efficiency (b) of Au-coated PCC11|LPSLI|NMC cell. Constant current density of $0.1 \mathrm{~mA} \mathrm{~cm}^{-2}$ was applied (Voltage window, 2.2-4.2 V). Black plot indicates CEs and red and blue plot charge and discharge capacity respectively. 

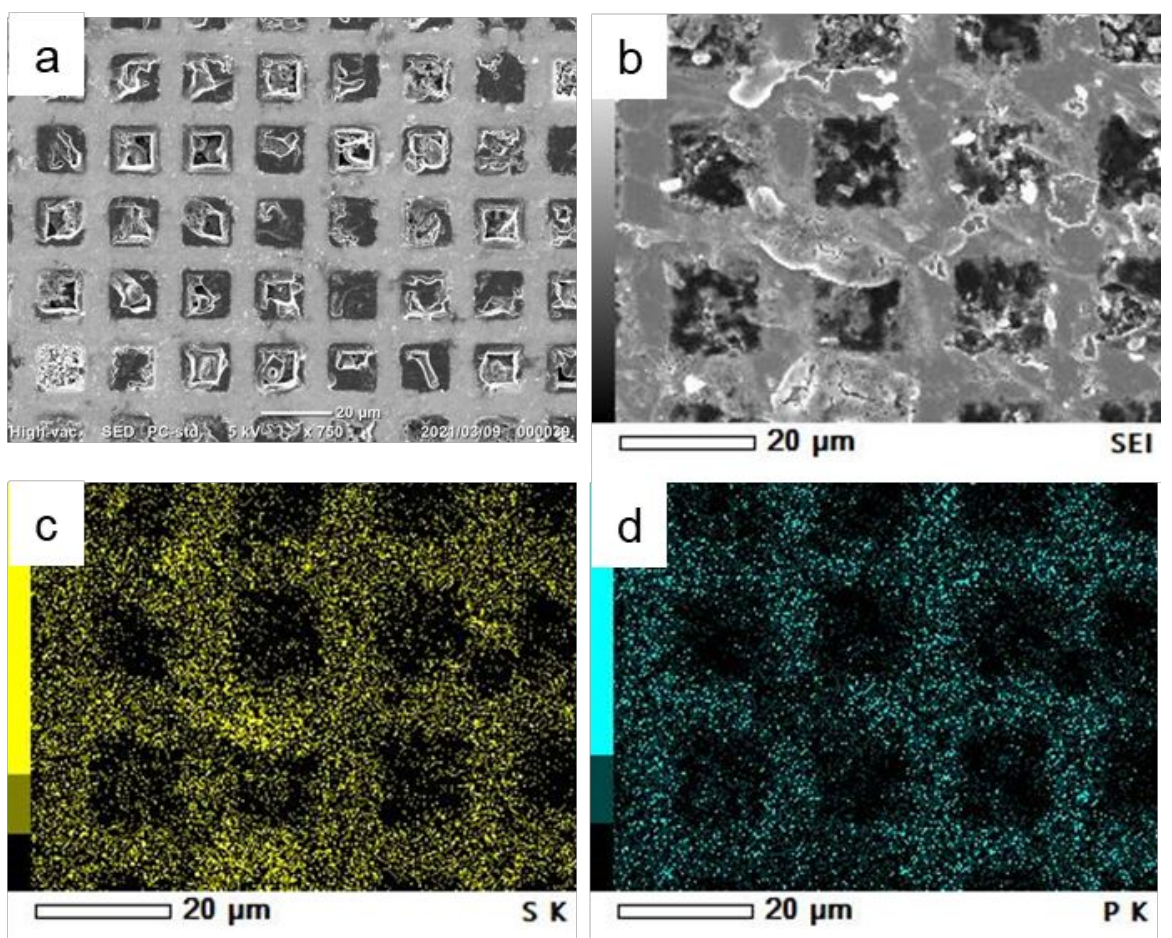

Figure S7 SEM images of (a) the back side and (b) the front side of the Au-coated PCC-11 after $50^{\text {th }}$ cycle at $0.1 \mathrm{~mA} \mathrm{~cm}^{-2}$. (d, e) EDS maps of the front side of the Au-coated PCC-11 after $50^{\text {th }}$ cycle at 0.1 $\mathrm{mA} \mathrm{cm}{ }^{-2}$. 

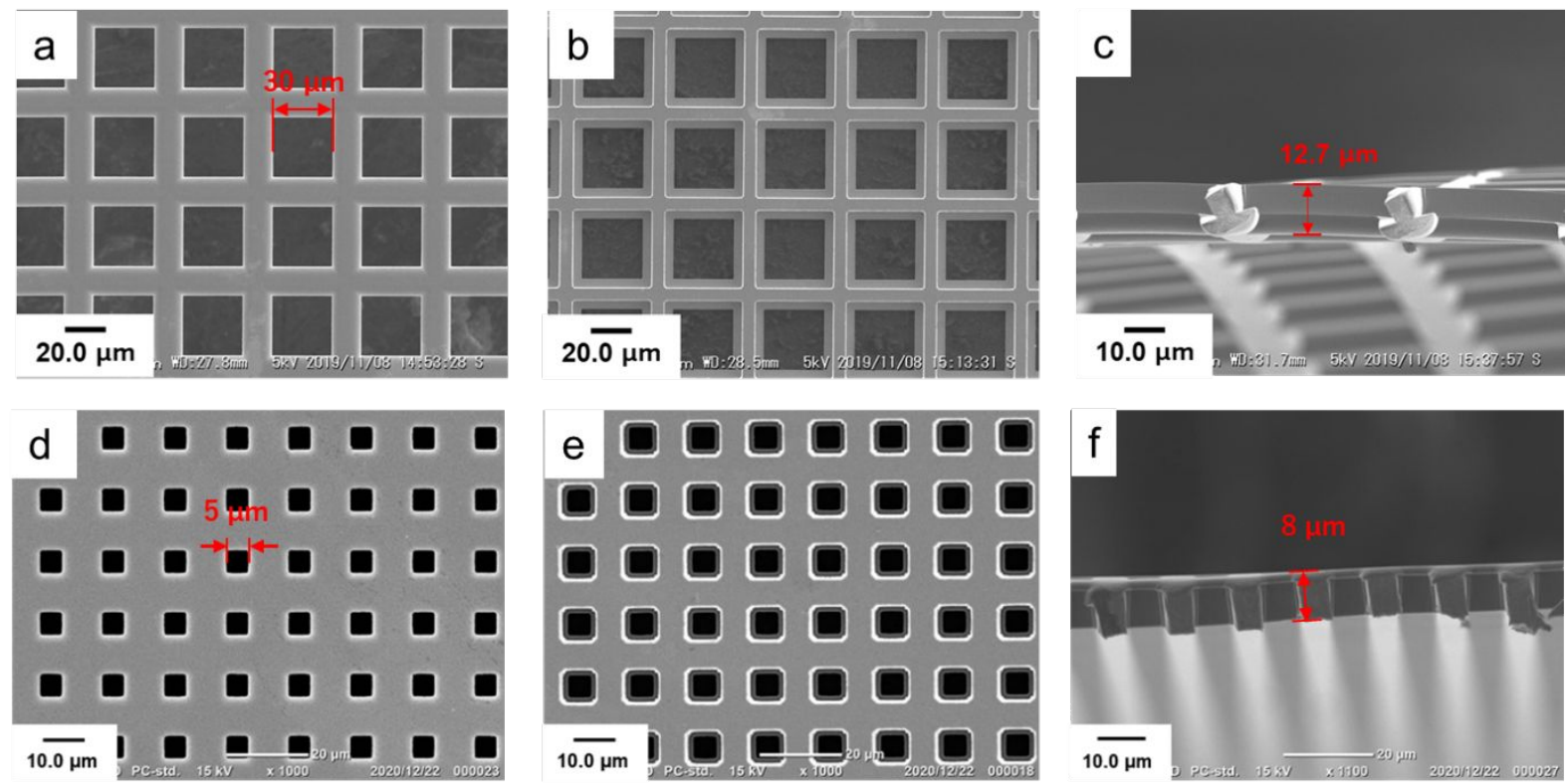

Figure S8 SEM images of (a) the back side, (b) the front side and (c) the cross section of PCC-30.

SEM images of (d) the back side, (e) the front side and (f) the cross section of PCC-5. 


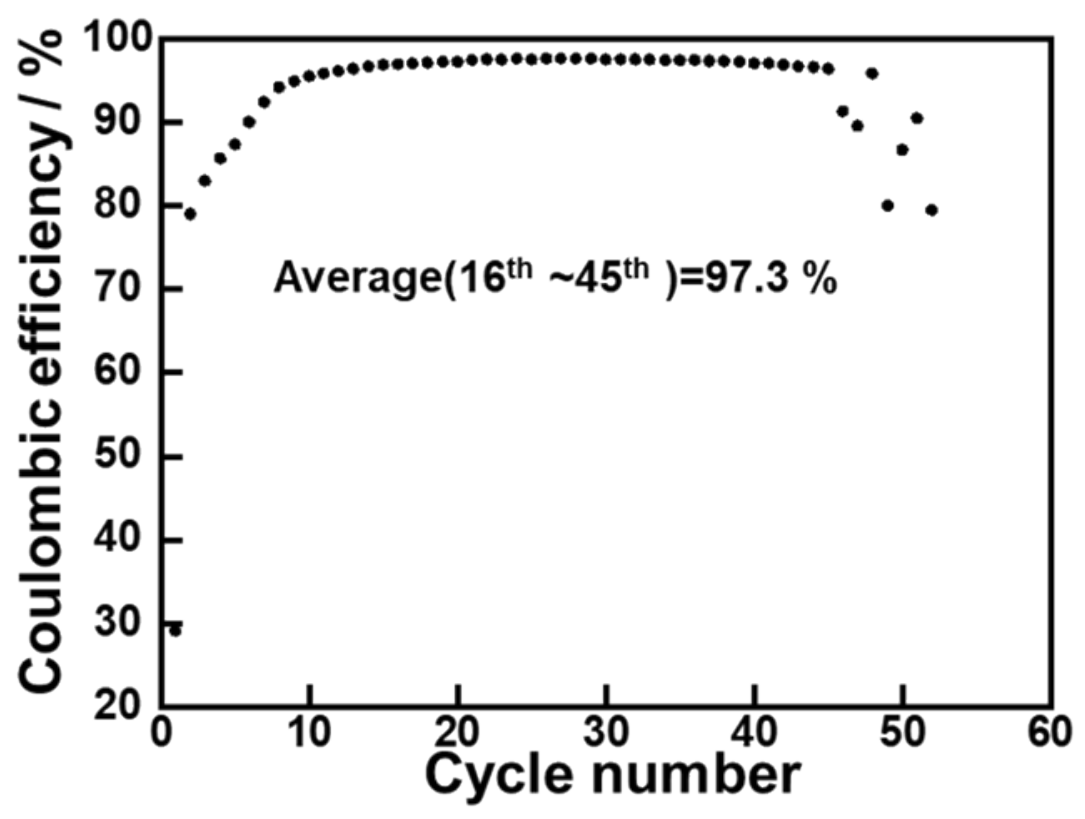

Figure S9 Coulombic efficiencies of cells using Au-coated PCC-11. The current density was $0.1 \mathrm{~mA}$ $\mathrm{cm}^{-1}$ and plating capacity was $0.2 \mathrm{mAh} \mathrm{cm}^{-2}$ for evaluating CE. 